\title{
Efficacy of Active Cycle of Breathing Technique on Functional Improvement in Post CABG Patient
}

\author{
Monisha $\mathrm{R}^{1 *}$ and TS Muthukumar ${ }^{2}$ \\ ${ }^{1}$ Assistant Professor, SRM College of Physiotherapy, India \\ ${ }^{2}$ Professor, Sri Ramakrishna College of Physiotherapy, India \\ *Corresponding author: Monisha R, Assistant Professor, India
}

Submission: 眥April 06, 2018; Published: 眥April 26, 2018

\begin{abstract}
Purpose: The purpose of this study was to evaluate the efficacy of active cycle of breathing techniques (ACBT) following coronary artery bypass graft (CABG) surgery. Material and methods: 15 patients with CABG were included in this study. Patients were evaluated using 6-minute walk test (6MWT), chest expansion and a 10-cm visual analogue scale for pain perception. Results: sixth and ninth day post-operatively, chest expansion and six minute walk test variables were significantly increased in both groups compared to pre-operative values.

Conclusion: ACBT improves functional capacity from the sixth to ninth day post-operatively. After a 5-day treatment, functional capacity was well preserved with the usage of ACBT. Respiratory physiotherapy methods had similar effects on the rate of atelectasis, pulmonary function, and pain perception.
\end{abstract}

Keywords: Physiotherapy; Coronary artery bypass surgery; Lung function tests; Exercise

\section{Background}

The number of people with CAD have sudden death as their first symptom, $50 \%$ of patient are diagnosed as having coronary artery disease in all over the world. Etiology behind this drastic increase is because of poor dietary habits and lack of physical activity. It is due to sedentary life styles and high stressful environment [1]. CAD is invited because of other risk factors like diabetes mellitus, hypertension and personal habits like smoking and alcoholism [2]. Due to lack of physical activity in majority of cases with CAD, diseases of the coronary arteries are due to atherosclerosis [3]. Cardiac arrest is the commonest cause for death in the world, 4.8 million men \& 4.4 million women in worldwide die each year because of CAD. When comparing the magnitude of CABG, it is the most common surgery performed in the world [4]. In India, the number of CABG is quite high, but the documented evidence of these official records is unavailable in some hospitals. The incidence of CAD varies greatly between countries and with advent of age correlates well with the mortality. From the past years, aim of the CABG is to relieve pain and to prolong life and also the long term survival depends not only on the operative procedure, but also on the extent of damage of the left ventricle [5].

Role of active cycle of breathing technique in CABG patients

Active cycle of breathing (ACBT) is an active breathing technique performed by the patient to help secretions from the main stem bronchus. This technique incorporated breathing exercises to improve the effectiveness of cough, loosen and clear secretions and improve the ventilation [6].

\section{Objective}

The use of anesthesia and blood loss coupled with restricted mobility and pain due to incision primarily affects the oxygen transport [7-9]. This leads to Sub -optimal muco-cilliary escalator, Decrease lung volume and capacities, Mucus retention and plugging in lungs and increased work of breathing. Because of pain, ventilation is further affected. However, pain relieving modalities and air way clearance techniques are available but nevertheless none of the technique so far as been shown to provide improvement [10]. Hence the postoperative treatment still remains in debate and lacks the much-needed practice. The ACBT focus on normalizing respiratory pattern, promoting airway clearance and reducing work of breathing. ACBT important to control the immediate postoperative complications.

\section{Method}

The purpose of this study is to record Efficacy of ACBT in reducing post operative co morbidities in CABG patients. The research has been done so that it may serve as a guideline for planning and implementing a study in a way that is most likely to achieve the goal in patients with post operative respiratory 
complications in CABG. The study was carried out for duration of 6 months and the treatment duration was carried out for the period of 6 days. The patients were treated daily for 40 minutes once daily and the values of the parameter selected were assessed on the $2^{\text {nd }}$ post operative day to $9^{\text {th }}$ post operative day. Before proceeding with

Table 1: Visual Analogue Scale.

\begin{tabular}{|c|c|c|c|c|}
\hline Sl. NO. & Pre test & Post test & $\left(x_{1}-x_{1}^{1}\right)$ & $\left(x_{1}-x_{1}{ }_{1}\right)^{2}$ \\
\hline 1 & 8 & 1 & -0.73 & 0.5 \\
\hline 2 & 9 & 2 & 0.27 & 0.07 \\
\hline 3 & 10 & 4 & 2.27 & 5.15 \\
\hline 4 & 8 & 3 & 0.27 & 0.07 \\
\hline 5 & 9 & 0 & 1.73 & 2.99 \\
\hline 6 & 6 & 2 & 0.27 & 0.07 \\
\hline 7 & 10 & 1 & 1.27 & 1.61 \\
\hline 8 & 8 & 1 & 0.27 & 0.07 \\
\hline 9 & 9 & 0 & 1.73 & 2.99 \\
\hline 10 & 7 & 2 & 0.27 & 0.07 \\
\hline 11 & 9 & 1 & -0.73 & 0.53 \\
\hline 12 & 10 & 3 & 1.27 & 1.61 \\
\hline 13 & 8 & 2 & 0.27 & 0.07 \\
\hline 14 & 9 & 1 & -0.73 & 0.53 \\
\hline 15 & 5 & 1 & -0.73 & 0.53 \\
\hline
\end{tabular}

Table 2: Chest Expansion.

\begin{tabular}{|c|c|c|c|c|}
\hline Sl. No. & Pre-test & Post-test & $\left(\mathbf{x}_{\mathbf{1}}-\mathbf{x}_{\mathbf{1}} \mathbf{}\right.$ & $\left(\mathbf{x}_{\mathbf{2}}-\mathbf{x}_{\mathbf{2}} \mathbf{1}^{\mathbf{2}}\right.$ \\
\hline 1 & 2 & 2.8 & 0.05 & 0.0025 \\
\hline 2 & 2.5 & 3 & 0.25 & 0.0625 \\
\hline 3 & 2.8 & 3.2 & 0.45 & 0.2025 \\
\hline 4 & 2.5 & 3.2 & 0.45 & 0.2025 \\
\hline 5 & 1.5 & 2 & -0.75 & 0.5625 \\
\hline 6 & 2 & 2.7 & -0.05 & 0.0025 \\
\hline 7 & 1.9 & 2.5 & -0.25 & 0.0625 \\
\hline 8 & 1.5 & 2 & -0.75 & 0.5625 \\
\hline 9 & 2.8 & 3.3 & 0.55 & 0.3025 \\
\hline 10 & 2.5 & 3.2 & 0.45 & 0.2025 \\
\hline 12 & 2 & 2.7 & -0.05 & 0.0025 \\
\hline 13 & 1.7 & 2.2 & -0.55 & 0.3025 \\
\hline 15 & 2.3 & 2.9 & 0.15 & 0.0225 \\
\hline
\end{tabular}

Table 3: Six Minute Walk Distance Test.

\begin{tabular}{|c|c|c|c|c|}
\hline SI. No. & Pre-test & Post-test & $\mathbf{X}_{\mathbf{1}}-\mathbf{X}_{\mathbf{1}}{ }^{\prime}$ & $\left(\mathbf{X}_{\mathbf{1}}-\mathbf{X}_{\mathbf{1}}{ }^{\prime}\right)^{\mathbf{2}}$ \\
\hline 1 & 5 & 1 & -0.47 & 0.2209 \\
\hline 2 & 7 & 1 & -0.47 & 0.2209 \\
\hline 3 & 6 & 3 & 1.53 & 2.3409 \\
\hline 4 & 4 & 1 & -0.47 & 0.2209 \\
\hline 5 & 5 & 1 & -0.47 & 0.2209 \\
\hline 6 & 6 & 2 & 0.53 & 0.2809 \\
\hline
\end{tabular}




\begin{tabular}{|c|c|c|c|c|}
\hline 7 & 5 & 1 & -0.47 & 0.2209 \\
\hline 8 & 6 & 1 & -0.47 & 0.2209 \\
\hline 9 & 5 & 1 & -0.47 & 0.2209 \\
\hline 10 & 4 & 2 & 0.53 & 0.2809 \\
\hline 11 & 6 & 2 & 0.53 & 0.2809 \\
\hline 12 & 4 & 1 & -0.47 & 0.2209 \\
\hline 14 & 5 & 2 & 0.53 & 0.2809 \\
\hline 15 & 6 & 1 & -0.47 & 0.2209 \\
\hline
\end{tabular}

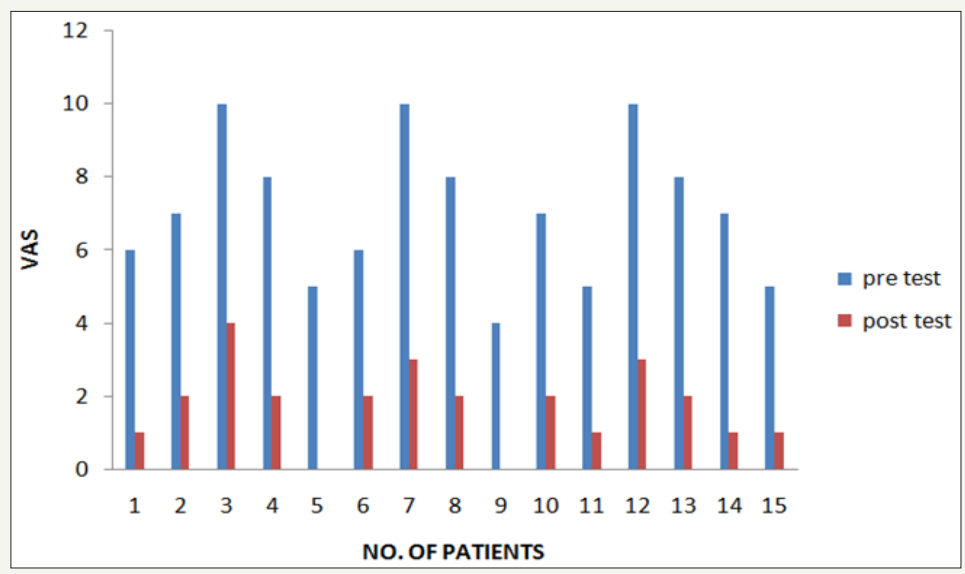

Figure 1: DATA of visual analogue scale.

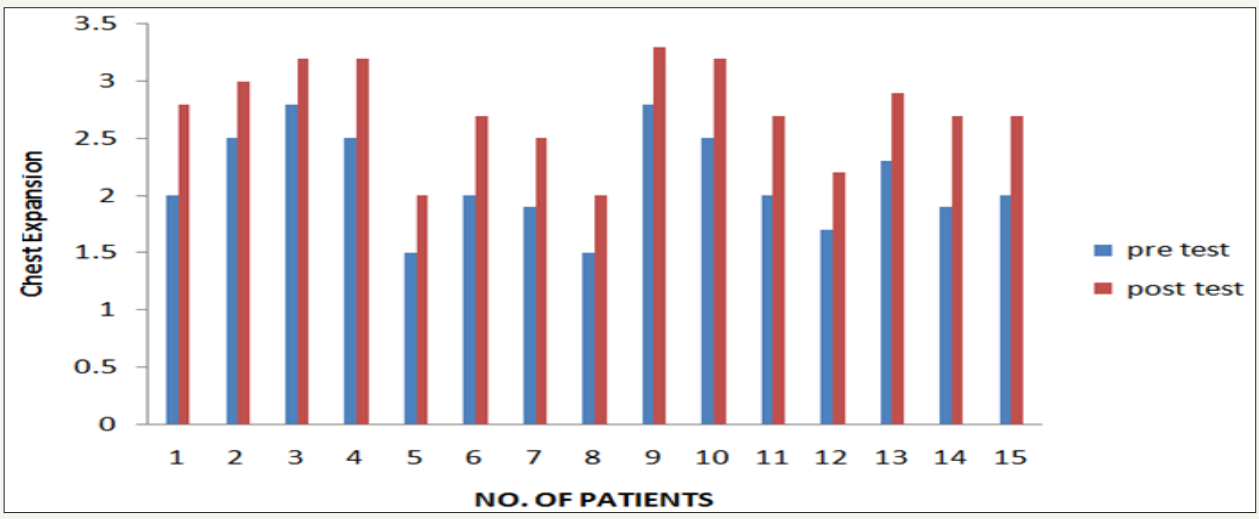

Figure 2: Chest expansion.

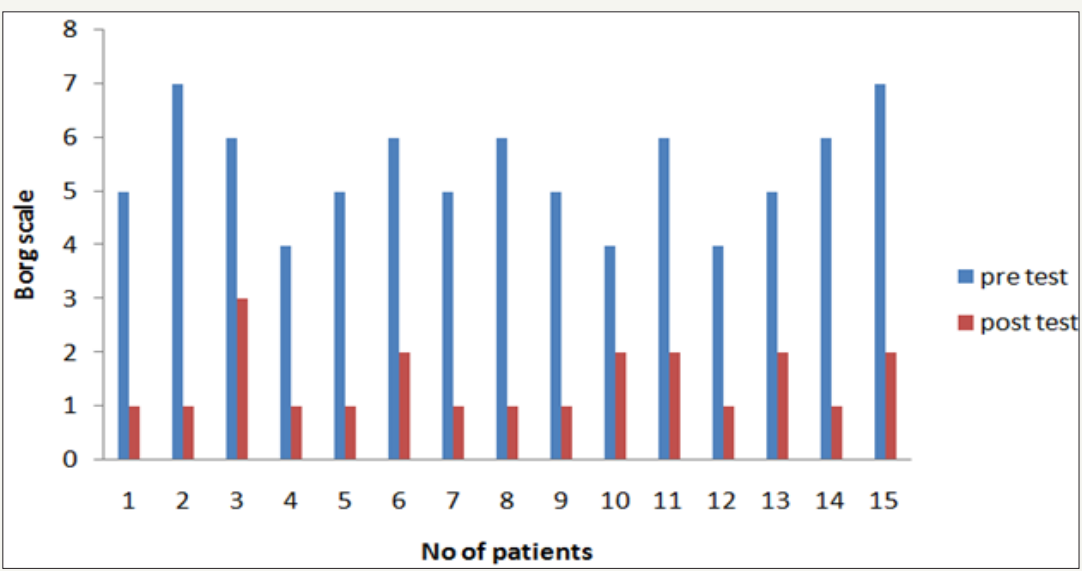

Figure 3: Six minutes walk test. 


\section{Discussion}

The purpose of this study is to determine the efficacy of Active Cycle of Breathing Technique. The study was conducted out for a period of 6 months with $28^{\circ}$ of freedom. Literature review states that there is significant difference between Active Cycle of Breathing techniques on post operative CABG patients. The result in various parameters was compared.

Early post-operative mobilization has been shown to increase lung volume, improve ventilation/perfusion matching, and mobilize secretion. In post CABG patients, impaired oxygen transport results in a deteriorated functional work capacity, and exercise capacity is one of the major concerns in post-operative recovery. Maximal oxygen uptake measured during a standard treadmill or bicycle test is the best available method to assess aerobic exercise capacity, 6MWT is a reliable alternative for measuring the functional exercise capacity. Because these tests require significant effort or special skills from the patients, walking tests have become a common method to determine functional capacity. To our knowledge, only 4 studies used 6MWT after cardiac surgery to provide reference values for defining disability. In this study, we used 6MWT to assess the efficacy of the ACBT after CABG in terms of effectiveness of functional capacity. Pre- and post-operative 6MWT distances were shown significant difference; chest expansion following CABG has attained a near normal value following ACBT at the end of treatment session

\section{Conclusion}

The Active Cycle of Breathing Technique is more effective method of treatment on post operative CABG patients.

\section{References}

1. Webber BA, Hofmeyr JL, Morgan MD (1986) Effects of postural drainage, incorporating the forced expiration technique, on pulmonary function in cystic fibrosis. Br J Dis Chest 80: 353-359.
2. Savci S, Inal-Ince D, Arikan HA (2000) Comparison of autogenic drainage and the active cycle of breathing techniques in patients with chronic obstructive pulmonary diseases. J Cardiopulm Rehabil 20(1): 37-43.

3. Inal-Ince D, Savci S, Topeli (2004) A Active cycle of breathing techniques in noninvasive ventilation for acute hypercapnic respiratory failure. Aust J Physiother 50(2): 67-73.

4. Knaus WA, Draper EA, Wagner DP (1985) APACHE II: a severity of disease classification system. Crit Care Med 13: 818-829.

5. Quanjer PH, Tammeling GJ, Cotes JE (1993) Lung volumes and forced ventilatory flows. Report Working Party Standardization of Lung Function Tests, European Community for Steel and Coal. Official Statement of the European Respiratory Society. Eur Respir J Suppl 16: 5-40.

6. (2002) ATS Committee on Proficiency Standards for Clinical Pulmonary Function Laboratories American Thoracic Society. ATS statement: guidelines for the six-minute walk test. Am J Respir Crit Care Med 166: 111- 117.

7. Enright PL, Sherill DL (1998) Reference equations for the six minutes walk in healthy adults. Am J Respir Crit Care Med 158: 1384-1387.

8. Westerdahl E, Lindmark B, Almgren SO (2001) Chest physiotherapy after coronary artery bypass graft surgery a comparison of three different deep breathing techniques. J Rehabil Med 33(2): 79-84.

9. Deloach LJ, Higgins MS, Caplan AB (1998) The visual analog scale in the immediate postoperative period: intrasubject variability and correlation with a numeric scale. Anaesth Analg 86: 102-106.

10. Green SB, Salkind NJ, Akey TM (2000) Using SPSS for Windows: Analyzing and Understanding Data. $\left(2^{\text {nd }}\right.$ edn), Prentice Hall, New Jersey, USA.

11. Westerdahl E, Lindmark B, Eriksson T (2003) The immediate effects of deep breathing exercises on atelectasis and oxygenation after cardiac surgery. Scand Cardiovasc J 37(6): 363-367.

12. Blaney F, Sawyer T (1997) Sonographic measurement of diaphragmatic motion after upper abdominal surgery: A comparison of three breathing manoeuvres. Inter J Physical Therapy 13(3): 207-215.
Creative Commons Attribution 4.0 International License

For possible submissions Click Here

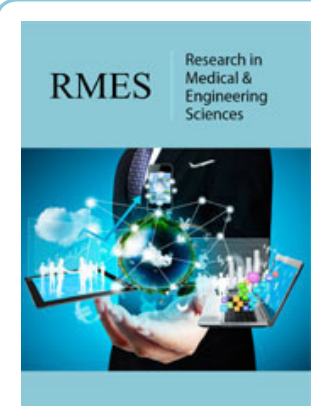

\section{Research in Medical \& Engineering Sciences}

\section{Benefits of Publishing with us}

- High-level peer review and editorial services

- Freely accessible online immediately upon publication

- Authors retain the copyright to their work

- Licensing it under a Creative Commons license

- Visibility through different online platforms 